\title{
Factors associated with psychological distress among young women in Kisumu, Kenya
}

\author{
This article was published in the following Dove Press journal: \\ International Journal of Women's Health \\ 2 May 2017 \\ Number of times this article has been viewed
}

\author{
Deborah A Gust' \\ Roman Gretadze' \\ Melissa Furtado ${ }^{2}$ \\ Mumbi Makanga ${ }^{3}$ \\ Victor Akelo ${ }^{3}$ \\ Kenneth Ondenge ${ }^{3}$ \\ Beatrice $\mathrm{Nyagol}^{3}$ \\ Eleanor McLellan-Lemal' \\ 'Division of HIV/AIDS Prevention, \\ Centers for Disease Control and \\ Prevention, ${ }^{2}$ Engility Corporation, \\ Atlanta, GA, USA; ${ }^{3} \mathrm{HIV}$ Research \\ Branch, Kenya Medical Research \\ Institute, Kisumu, Kenya
}

Correspondence: Deborah A Gust Clinical Trials Team, Epidemiology Branch, Division of HIVIAIDS Prevention, Centers for Disease Control and Prevention, 1600 Clifton Road, Mail-Stop E-45, Atlanta, GA 30333, USA

Fax + I 4046396127 Email dgust@cdc.gov
Background: Attention to mental health issues is growing globally. In many countries, including Kenya, however, assessment of psychological distress, especially in rural areas, is limited.

Methods: We analyzed data from young women screened for a longitudinal contraceptive ring study in Kisumu, Kenya. Multivariable regression analysis was used to assess factors associated with recent moderate and high psychological distress, as measured by the Kessler (K-6) psychological distress scale.

Results: Among the 461 women screened, most (58.4\%) were categorized as having moderate psychological distress, $20.8 \%$ were categorized as having low or no psychological distress, and $20.8 \%$ were categorized as having high psychological distress. Moderate psychological distress (vs low/no) was significantly more likely among women who reported a history of forced sex and were concerned about recent food insecurity. High (vs low/no) psychological distress was significantly more likely among women who reported a history of forced sex, who were concerned about recent food insecurity, and who self-reported a sexually transmitted infection.

Conclusion: To reduce psychological distress, a focus on prevention as well as care methods is needed. Girls need a path toward a healthy and productive adulthood with a focus on education, which would help them gain skills to avoid forced sex. Women would benefit from easy access to social services and supports that would help them with basic needs like food security among other things. A holistic or ecological approach to services that would address mental, educational, social, health, and economic issues may have the highest chance of having a longterm positive impact on public health.

Keywords: forced sex, food insecurity, HIV, holistic

\section{Introduction}

Psychological distress is a state of emotional suffering that is generally characterized by symptoms of depression and anxiety. ${ }^{1}$ It has been recognized increasingly that health issues related to mental, behavioral, and neurological disorders are growing throughout the world. Such disorders are responsible for $10.4 \%$ of all disabilityadjusted life years lost or lived with a disability. ${ }^{2}$ Importantly, over three-quarters of the burden is in low- and middle-income countries, where the health infrastructure is least able to address it. ${ }^{3}$

The study of psychological distress among persons in African countries is sparse; however, individual and socio-cultural factors, such as female gender, lower education and lower socioeconomic status, ${ }^{4}$ lack of social support, ${ }^{5}$ and stressful life events, ${ }^{6}$ have been shown to be important contributors. In a study conducted in Ghana, nearly $20 \%$ of men and women reported having moderate or severe psychological distress. The prevalence varied according to gender, marital status, education, wealth, religion, and self-reported poor health status. In addition, among women in relationships, those who 
reported having experienced physical abuse, who reported having high levels of partner control, and who were more accepting of existing gender inequality, had greater odds of reporting psychological distress. ${ }^{7}$ In a Kenyan household survey study in Nyanza Province, the prevalence of common mental disorders (eg, mixed anxiety/depression, panic disorder, generalized anxiety disorder) was $10.8 \%$, with higher rates of mental disorders among persons who were older and persons with poor physical health. ${ }^{8}$ The co-occurrence of psychological and physical illness has been found globally in rich, middle-income, and low-income countries, such as Kenya. ${ }^{8}$ Given the high prevalence of HIV in sub-Saharan Africa, ${ }^{9}$ it is especially important to assess psychological disorders, for instance depression, ${ }^{10}$ and even difficulty with coping skills in response to negative daily life events, ${ }^{11}$ as these can affect behaviors that place people at higher risk for HIV and other sexually transmitted infections (STIs). Moreover, persons infected with HIV who also have depression or other psychological disorders have difficulty with selfcare, which includes medication adherence ${ }^{12}$ and successful participation in a linkage to care intervention. ${ }^{13}$

Psychological distress has not been well studied in developing countries. To add to the literature on factors associated with psychological distress in high burden HIV sub-Saharan settings, we conducted a planned analysis of screening data collected to determine the acceptability of an intravaginal ring (IVR) to prevent pregnancy among young women in Kisumu, Kenya. The objectives were to determine, among women, 1) the prevalence of psychological distress as measured by the Kessler (K-6) psychological distress scale and 2) factors associated with psychological distress.

\section{Methods}

Screening data for a longitudinal IVR acceptability and use study were collected from April 2014 through November 2014. Following a community engagement process to create awareness about the study and establish initial as well as on-going collaboration with community stakeholders, women were recruited from family planning clinics within Kisumu County, via 10 community health workers, and participant word-of-mouth referrals without incentives using convenience sampling. We recruited women who were using contraceptives and who were 18-34 years of age, were sexually active in the past 3 months on more than one occasion, were not currently pregnant and not intending to get pregnant for the next 12 months, neither breastfeeding nor within 3 months of parturition at screening, had not used a long-term hormonal contraceptive in the past 3 months, lived in the Kisumu catchment area $(\sim 150 \mathrm{~km}$ from Kisumu City), and were within 30 days of their last oral contraceptive scheduled visit or within 3 months of receipt of their last depot medroxyprogesterone acetate injection. The women also had to be willing to undergo monthly pregnancy testing, periodic pelvic examinations, and HIV testing and interviews at screening, 3 months, and 6 months after study enrollment. Finally, they had to be able to understand and read English, Dholuo, or Swahili, comprehend study procedures and provide signed informed consent. The study was approved by the Scientific Steering and Ethical Review Committees of the Kenya Medical Research Institute (KEMRI), an Institutional Review Board for the United States Centers for Disease Control (CDC), and the Kenya Pharmacy and Poisons Board. Women who completed the in-depth screening process received a bar of soap, 500 Kenya Shillings ( $\sim$ \$ USD) for transport, feminine sanitary pads, and a treated malaria bed net in accordance with local reimbursement practices.

\section{Procedures}

After completing a brief prescreening computer-assisted personal interview (CAPI), all women who met preliminary eligibility criteria consented to complete in-depth screening procedures. Women completed audio computerassisted interview (ACASI), provided a CAPI gynecological medical history, and underwent a pelvic examination. Questions covered included those regarding demographic characteristics, reasons for taking part in the study, use of medications and adherence, concern about food insecurity, communication with partner about contraception and how many children to have, ever physically hurt or threatened to hurt by a sexual partner, sexual history, risk behaviors, STI in the last 3 months, and the K-6 psychological distress scale. Pregnancy, HIV, and STI testing were conducted according to the Kenya National Guidelines. ${ }^{14}$ The questionnaires were available in the three local languages (English, Dholuo, or Swahili). Participants were able to select the language of their choice for CAPI and ACASI questionnaire administration. Staff were trained prior to and during data collection on understanding the intent of each question. Participants completed a self-directed ACASI tutorial before using the computer to answer questions.

\section{Measures}

The dependent variable used in the analyses was psychological distress during the last 30 days using responses to the K-6 psychological distress scale, ${ }^{15}$ which is used for the World Health Organization (WHO) World Mental Health 
Survey initiative.${ }^{16}$ While anxiety and depression symptoms are included in the K-6 scale, it is classified as measuring nonspecific distress as opposed to a clinical diagnosis of a specific mental disorder. ${ }^{1,15}$ The K-6 has been validated in sub-Saharan African countries. ${ }^{16-19}$ Questions were asked about how the person has been feeling during the past 30 days and how often they felt that way, that is, During the last 30 days, how often did you feel ... nervous, ... hopeless, ... fidgety, ... so depressed that nothing could cheer you up, $\ldots$ that everything was an effort, ... worthless? The scale discriminates with precision between community cases and non-cases of Diagnostic and Statistical Manual of Mental Disorders- $I V$ disorders such as anxiety and mood disorders. ${ }^{15}$ For our analysis, K-6 psychological distress scale responses ranged from 0 (none of the time) to 4 (all of the time). To calculate the final total score, we summed across these six items for a scale score ranging from 0 to 24 . The total scores were grouped into three categories (low/no distress: 0-4; moderate distress: 5-12; high distress: 13-24) based on previously identified thresholds for moderate as well as severe psychological distress. ${ }^{15,16,20,21}$

Independent variables included age, ethnic group, marital status, religion, education, occupation, main source of income, concern about having enough food for self and family (henceforth referred to as food insecurity) in the past 30 days, being inherited after the death of a spouse, perceived overall health status, age at first sex, unprotected vaginal or anal sex in past 3 months, transactional sex history, recent transactional sex, HIV-infected partners in past 3 months, ever experienced forced sex, ever physically hurt or threatened to hurt by sex partner, got into trouble with family/ friends, missed school, or got into fights because of drinking, ever used drugs, drug use in past 30 days, person making decision as to when to stop bearing children (woman, man, both), person making decision on avoiding childbearing (woman, man, both), self-reported STI in the past 3 months, and HIV test results. Being inherited after the death of a spouse refers to the Luo cultural practice in which a widow is required to marry a male relative of her late husband (often his brother) or in more recent times, a professional inheritor receives money or types of payment for inheriting a widow. ${ }^{22}$

\section{Statistical analysis}

Data for this analysis were restricted to the baseline data. We excluded from the analysis two person's screening data, given technical issues with their ACASI data. Categorical variables were summarized using frequency counts and percentages. Multinomial logistic regression was used to determine factors independently associated with psychological distress (high vs low/no distress and moderate vs low/no distress). Selection of predictor variables into a multivariable model and subsequent backward elimination was directed by the chi-square test using 0.25 level of significance as a cutoff. All statistical tests were two-sided and were interpreted at 0.05 level of significance. The analyses for this article were performed using SAS for Windows version 9.3 (SAS Institute, Inc., Cary, NC, USA).

\section{Results}

Four hundred sixty-one women underwent ACASI study screening. Most of the women screened were of Luo ethnicity (90.9\%), married or cohabiting (67.9\%), had primary school education or less $(68.2 \%)$, and were employed (63.4\%). Nearly half (47.3\%) the women screened were $18-24$ years of age. Other descriptive information can be found in Table 1. HIV prevalence at baseline was $14.4 \%$ (Table 2).

Table I Demographic and lifestyle characteristics of women screened for contraceptive ring study $(n=46 I)$, Kisumu, Kenya, 2014

\begin{tabular}{|c|c|}
\hline Variable & Total N (\%) \\
\hline \multicolumn{2}{|l|}{ Age at screening, years } \\
\hline $18-24$ & $218(47.3)$ \\
\hline $25-29$ & $168(36.4)$ \\
\hline $30-34$ & $75(16.3)$ \\
\hline \multicolumn{2}{|l|}{ Ethnic group } \\
\hline Luo & $4 \mid 8(90.9)$ \\
\hline Non-Luo & $42(9.1)$ \\
\hline \multicolumn{2}{|l|}{ Marital status } \\
\hline Single & 81 (I7.9) \\
\hline Married/cohabiting & 307 (67.9) \\
\hline Other & $64(14.2)$ \\
\hline \multicolumn{2}{|l|}{ Religion } \\
\hline Roman Catholic & $206(44.8)$ \\
\hline Other Christian & $172(37.4)$ \\
\hline Other non-Christian & $82(17.8)$ \\
\hline \multicolumn{2}{|l|}{ Education } \\
\hline None & $17(3.7)$ \\
\hline Primary (any) & $296(64.5)$ \\
\hline Secondary (any) & $126(27.5)$ \\
\hline Tertiary & $20(4.4)$ \\
\hline \multicolumn{2}{|l|}{ Occupation } \\
\hline Employed & $291(63.4)$ \\
\hline Unemployed & $168(36.6)$ \\
\hline \multicolumn{2}{|l|}{ Main source of income } \\
\hline None & $22(4.8)$ \\
\hline Salary-based & $256(55.7)$ \\
\hline Not salary-based & $182(39.6)$ \\
\hline \multicolumn{2}{|l|}{ Number of live births } \\
\hline 0 & $6(1.3)$ \\
\hline $1-2$ & $238(53.2)$ \\
\hline$\geq 3$ & $203(45.4)$ \\
\hline
\end{tabular}

Notes: The sum does not always add to 461 because of missing values. The percentage in each cell is computed using the total number of non-missing records as the denominator. 


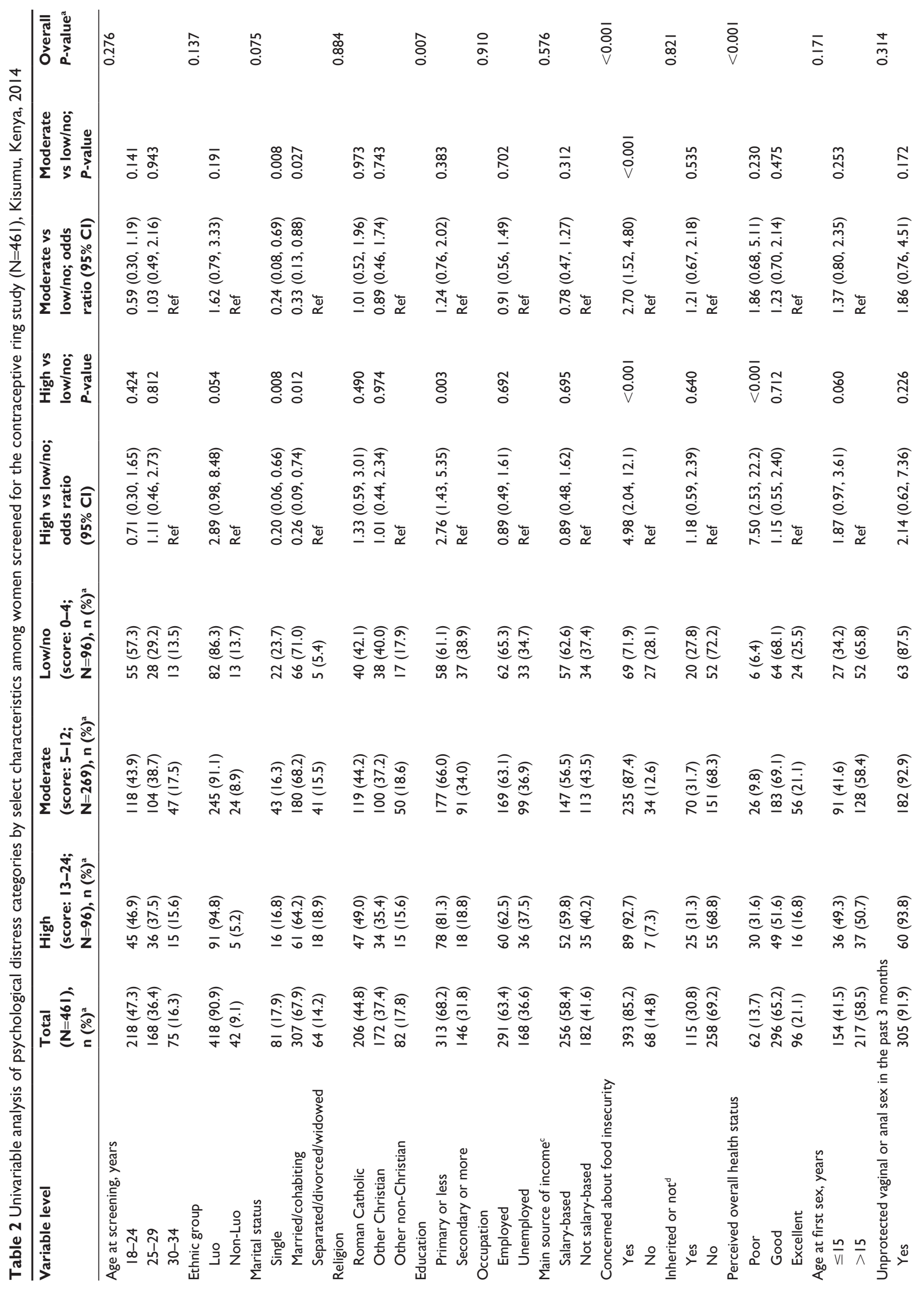




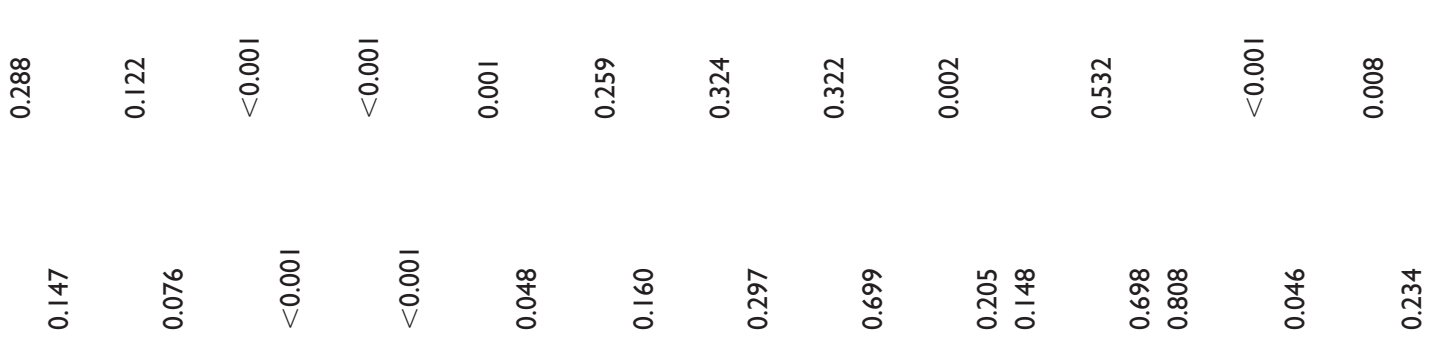

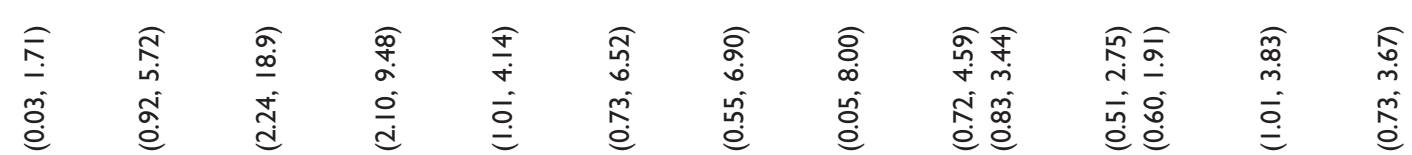

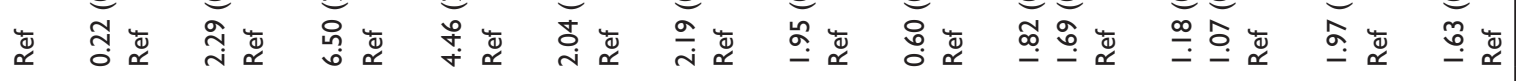

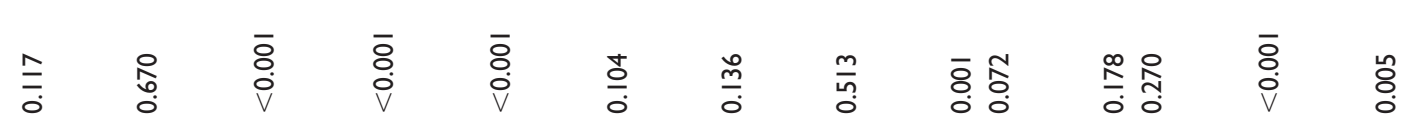

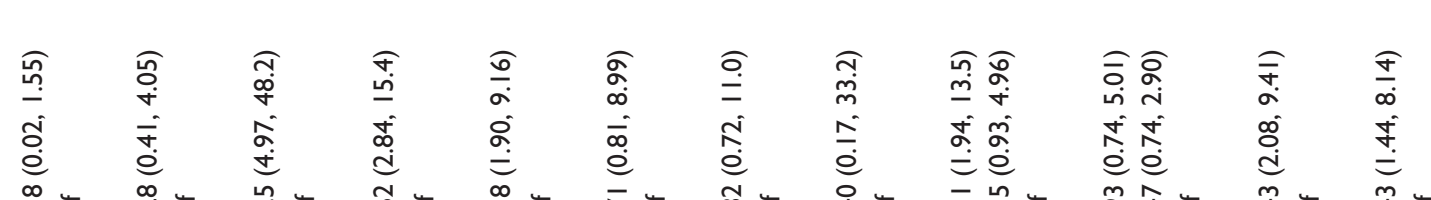

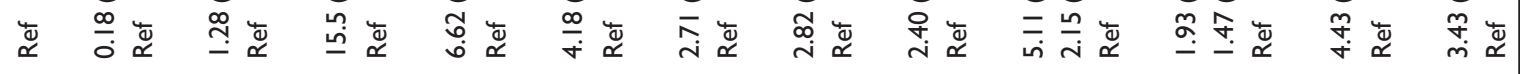

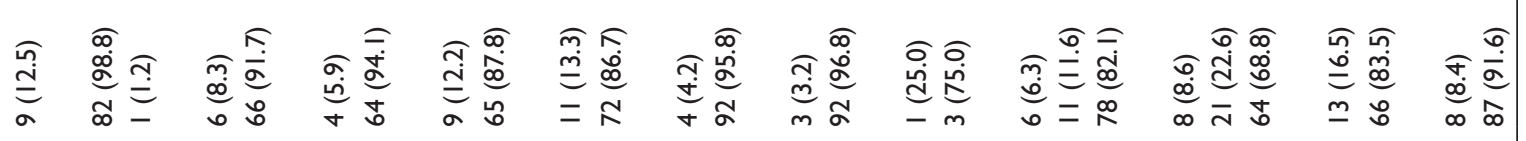

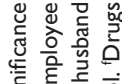

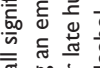

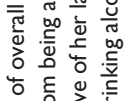

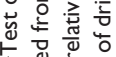

言总舫

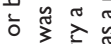

है है

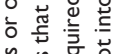

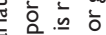

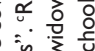

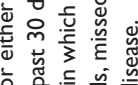

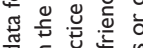

no

है

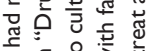

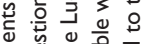

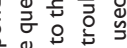

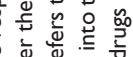

势过

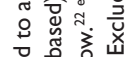

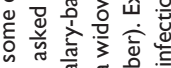

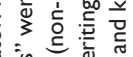

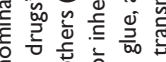

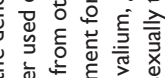

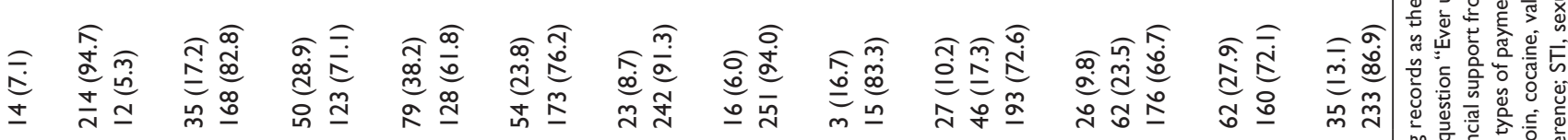

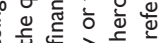

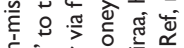

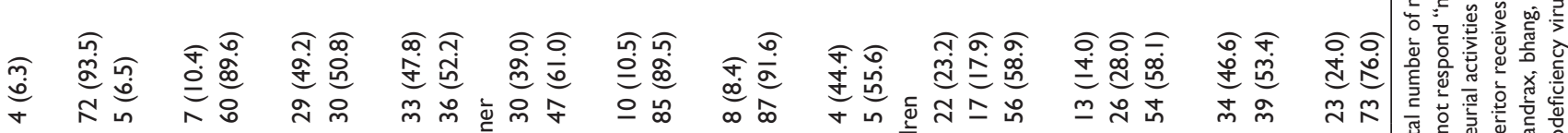

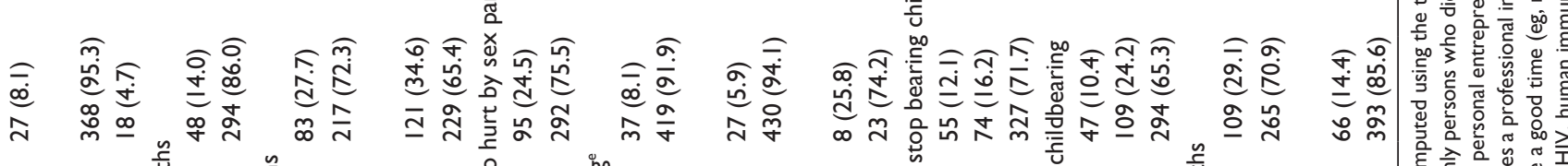

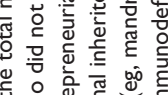

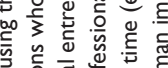

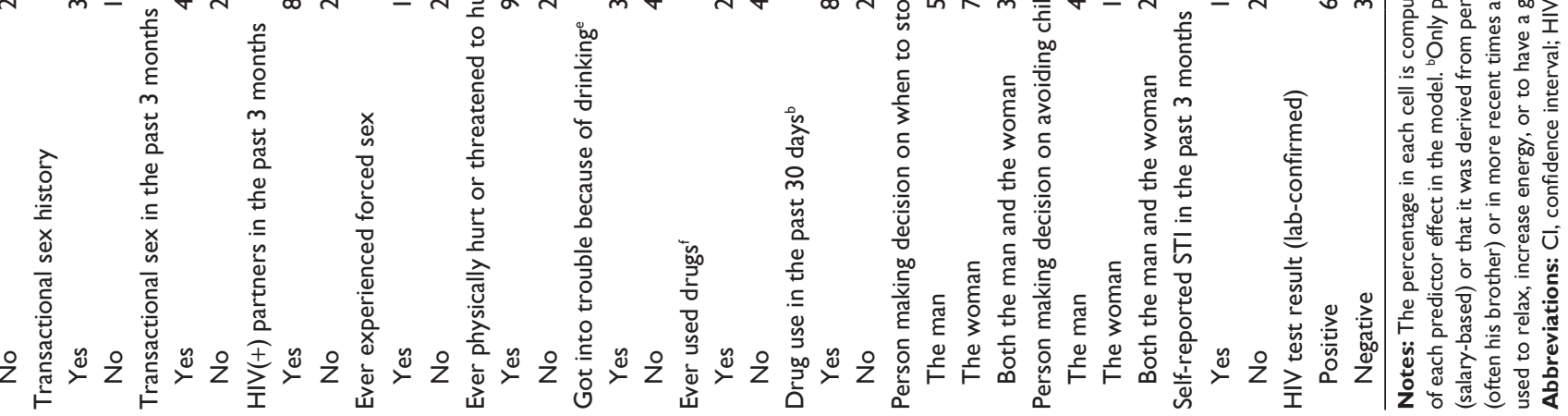


Most women (58.4\%) scored in the moderate range (5-12) of the K-6 psychological distress scale, with an equal percent $(20.8 \%)$ scoring on the low/no side (0-4) and the high side (13-24) of the scale. The proportion of HIV-infected women in the three psychological distress categories was as follows: low/no (8.4\%), moderate $(13.1 \%)$, and high $(24.0 \%)$ (Table 2). In univariate analysis, the odds of HIV positivity was more than three times higher (odds ratio $[\mathrm{OR}]=3.43$, confidence interval $[\mathrm{CI}]=1.44,8.14$ ) among women whose psychological distress was high compared to low/no distress. However, this significant association fell out of the multivariable model described below.

Based on univariable analysis (Table 2), 13 variables were included in the multivariable model: ethnic group, marital status, education, concern about food insecurity, perceived overall health status, age at first sex, recent transactional sex, HIV+ partners in past 3 months, ever experienced forced sex, ever physically hurt or threatened to hurt by sex partner, person making decision on when to stop bearing children, self-reported STI, and HIV test result. In the final model (Table 3), moderate (vs low/no) psychological distress was significantly more likely among women who reported ever experiencing forced sex (adjusted odds ratio $[\mathrm{aOR}]=4.27 ; 95 \% \mathrm{CI}=1.91-9.53$ ) and among women who were concerned about food insecurity $(\mathrm{aOR}=2.39 ; 95 \%$ $\mathrm{CI}=1.22-4.67$ ). High (vs low/no) psychological distress was significantly more likely among women who reported ever experiencing forced $\operatorname{sex}(\mathrm{aOR}=6.06 ; 95 \% \mathrm{CI}=2.43-15.1)$, who were concerned about food insecurity $(\mathrm{aOR}=3.65$; $95 \%$ CI $=1.23-10.9)$, and who self-reported an STI in the past 3 months ( $\mathrm{aOR}=4.02 ; 95 \% \mathrm{CI}=1.65-9.83$ ). It is of note that high (vs low/no) psychological distress was more likely among women with lower education ( $\mathrm{aOR}=2.17 ; 95 \%$ $\mathrm{CI}=0.99-4.77)$, but the $P$-value was slightly higher than the 0.05 cutoff $(0.053)$.

\section{Discussion}

Among young Kenyan women screened for the study, 58\% had moderate and $21 \%$ had high psychological distress as measured by the K-6 scale. While not a direct comparison, a US survey that used a stratified sample designed to provide estimates for the civilian noninstitutionalized population found that among women aged $\geq 18$ years, only $3.9 \%$ had high psychological distress as measured by the K-6 scale. ${ }^{23}$ Other studies touching on psychiatric issues in Kenya, which did not use the K-6 scale, found a $10.8 \%$ prevalence of common mental disorders (eg, depressive episodes, panic disorder, obsessive-compulsive disorder) among a rural general population determined using the Clinical Interview Schedule - Revised and the Psychosis Screening Questionnaire ${ }^{24}$ and a $20 \%$ prevalence of psychiatric disorders (eg, anxiety and depression) among patients in a clinic determined using a systematic psychiatric interview. ${ }^{25}$ Prevalence of non-specific psychological distress is important from a holistic health perspective because, as noted by the WHO in their constitution, "Health is a state of complete physical, mental and social well-being and not

Table 3 Final multivariable model for psychological distress among women screened for the contraceptive ring study ( $N=342)$, Kisumu, Kenya, 2014

\begin{tabular}{|c|c|c|c|c|c|c|c|c|c|}
\hline $\begin{array}{l}\text { Variable } \\
\text { level }\end{array}$ & $\begin{array}{l}\text { Total } \\
(\mathrm{N}=342) \\
\mathrm{n}(\%)\end{array}$ & $\begin{array}{l}\text { High } \\
\text { (score: I 3-24) } \\
(\mathrm{N}=68), \mathrm{n}(\%)\end{array}$ & $\begin{array}{l}\text { Moderate } \\
\text { (score: 5-I2) } \\
(\mathrm{N}=\mathbf{2 0} 1) \text {, n (\%) }\end{array}$ & $\begin{array}{l}\text { Low/no } \\
\text { (score: 0-4) } \\
(\mathbf{N}=73), \mathrm{n}(\%)\end{array}$ & $\begin{array}{l}\text { High vs lowl } \\
\text { no; adj odds } \\
\text { ratio }(95 \% \mathrm{Cl})\end{array}$ & $\begin{array}{l}\text { High vs } \\
\text { low/no; adj } \\
\text { P-value }\end{array}$ & $\begin{array}{l}\text { Moderate vs } \\
\text { low/no; adj odds } \\
\text { ratio }(95 \% \mathrm{CI})\end{array}$ & $\begin{array}{l}\text { Moderate } \\
\text { vs low/no; } \\
\text { adj P-value }\end{array}$ & $\begin{array}{l}\text { Overall, } \\
\text { adj } \\
\text { P-value }^{a}\end{array}$ \\
\hline Education & & & & & & & & & 0.150 \\
\hline $\begin{array}{l}\text { Primary } \\
\text { or less }\end{array}$ & $219(64.0)$ & $52(76.5)$ & $127(63.2)$ & $40(54.8)$ & $2.17(0.99,4.77)$ & 0.053 & $\mathrm{I} .33(0.74,2.39)$ & 0.334 & \\
\hline $\begin{array}{l}\text { Secondary } \\
\text { or more }\end{array}$ & $123(36.0)$ & $16(23.5)$ & $74(36.8)$ & $33(45.2)$ & Ref & & Ref & & \\
\hline \multicolumn{9}{|c|}{ Concerned about food insecurity } & 0.014 \\
\hline Yes & $286(83.6)$ & $63(92.6)$ & $174(86.6)$ & $49(67.1)$ & $3.65(1.23,10.9)$ & 0.020 & $2.39(1.22,4.67)$ & 0.011 & \\
\hline No & $56(16.4)$ & $5(7.4)$ & $27(13.4)$ & $24(32.9)$ & Ref & & Ref & & \\
\hline \multicolumn{9}{|c|}{ Ever experienced forced sex } & $<0.001$ \\
\hline Yes & II 3 (33.0) & $32(47.1)$ & $73(36.3)$ & $8(I I .0)$ & $6.06(2.43,15.1)$ & $<0.001$ & $4.27(1.91,9.53)$ & $<0.001$ & \\
\hline No & $229(67.0)$ & $36(52.9)$ & $128(63.7)$ & $65(89.0)$ & Ref & & Ref & & \\
\hline \multicolumn{9}{|c|}{ Self-reported STI in past 3 months } & 0.002 \\
\hline Yes & $82(24.0)$ & $29(42.6)$ & $44(21.9)$ & $9(12.3)$ & $4.02(1.65,9.83)$ & 0.002 & $\mathrm{I} .62(0.72,3.62)$ & 0.240 & \\
\hline No & $260(76.0)$ & $39(57.4)$ & I57 (78. I) & $64(87.7)$ & Ref & & Ref & & \\
\hline
\end{tabular}

Notes: The percentage in each cell is computed using the total number of non-missing records as the denominator. In some cases, the respondents had missing data for

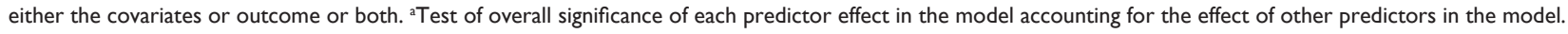
Abbreviations: $\mathrm{Cl}$, confidence interval; Ref, reference; adj, adjusted; STI, sexually transmitted infections. 
merely the absence of disease or infirmity". ${ }^{26}$ Public health, including physical and mental health, is influenced not only by individual characteristics but also by social, cultural, economic, and political factors. ${ }^{27}$

In our study, ever experiencing forced sex was associated with both moderate and high psychological distress among young women using contraceptive. Forced sex was experienced by more than a third (34.6\%) of the women in our study of whom the majority were of Luo ethnicity (90.9\%) and married or cohabitating (67.9\%). Other studies in subSaharan Africa have reported on forced sex. For instance, among teenagers in Ghana, the prevalence of forced sex was $18 \%$ and $13 \%$ in two waves of a cross-sectional survey, ${ }^{28}$ and among women in Botswana and Swaziland, the prevalence was $10.3 \%$ and $11.4 \%$, respectively. ${ }^{29}$ Sexual roles and gender scripts in sub-Saharan African countries influence sexual experiences including sexual assault. ${ }^{30}$ Biases in favor of male children disenfranchise girls and this can make them more vulnerable to forced sex. ${ }^{31}$ Males are raised in a culture of male dominance, resulting in little couple communication about sex. ${ }^{32}$ Moreover, there are many Luo customary practices that involve sex, including construction of a house, marriage of children, the death of a spouse, and agricultural practices. These customary practices are required and if not followed, have a predetermined consequence of defying the cultural tradition called "chira", ${ }^{33}$ which can affect food insecurity. For instance, if sex is not performed before the harvest, the crops cannot be brought in. ${ }^{33}$ Women may not always be willing participants and thus lack control in these customary practices. Lack of control over one's own sexuality has been associated with psychological distress in a previous study in Ghana. ${ }^{34}$

Our study showed that concern about food insecurity within the past 30 days was common across all psychological distress categories $(85.2 \%)$ and was associated with both moderate and high psychological distress among young women. While the relationship between food insecurity and physical health has been demonstrated, ${ }^{35}$ less attention has been paid to the relationship between a lack of food access and psychological health. ${ }^{36}$ A systematic review of the literature found that individuals in developing countries who experienced food insecurity were more likely to have elevated anxiety, depression, and other symptoms of common psychological disorders than individuals who did not experience food insecurity. ${ }^{37}$ Food insecurity can have effects on at least two levels. Insecurity can cause a feeling of lack of control, which can result in disorders such as depression and anxiety, and lack of adequate nutrition can adversely affect brain function, including cognition and mood regulation; lack of proper nutrition has been shown to be associated with disorders such as depression and anxiety. ${ }^{38-41}$

Self-report of an STI in the past 3 months in our study was cited by nearly $30 \%$ of respondents and was independently associated with high psychological distress. Among women in South Africa who were recently sexually active, those reporting psychosocial problems also reported a greater proportion of condomless sex, ${ }^{42}$ and among adults in South Africa, post-traumatic stress disorder was associated with STI risk behaviors such as alcohol and/or drug use before sex and condomless sex. ${ }^{43}$ In addition, being told that one has an STI can bring on psychological distress. ${ }^{44}$

Our descriptive results showed that the proportion of HIV-infected women was highest in the high psychological distress category $(24.0 \%)$ compared to the moderate psychological distress $(13.1 \%)$, and the low or no distress $(8.4 \%)$ categories. The univariate analysis showed an overall significant relationship between HIV positivity and higher psychological distress not found in the multivariable analysis. This finding corresponds with the literature indicating that mental health problems are associated with HIV risk behaviors and HIV infection. ${ }^{45,46}$ It also corresponds to a systematic review of African studies that found that people living with HIV or AIDS have more mental health problems than persons who are not HIV infected. ${ }^{47}$ Services related to the psychological health and wellness of persons in Kenya, especially those at high risk for HIV and those infected with HIV, are much needed. ${ }^{48}$

\section{Limitations}

Our study had several limitations. 1) Our sample size was limited and convenience sampling was used to recruit participants; thus, the women in our study may not be representative of women residing in the Kisumu catchment area. 2) We were not able to determine causality in stating that certain variables contributed to psychological distress. 3) Numbers of HIV-infected persons in the low-to-no psychological distress category were low, and this may have limited statistical power in the multivariable analyses. 4) Some potentially important variables were not included in our analysis due to omission (eg, attempted or suicidal thoughts, and parental discussion about sex) or low numbers (eg, exchange of food for sex). A strength of our study is that it provides information about the important issue of psychological distress in an African setting where little published information is available. 


\section{Conclusion}

Nearly $80 \%$ of women in our study had moderate or high psychological distress as measured by the K-6 scale. Experiencing forced sex and concern about food insecurity was significantly associated with both moderate and high psychological distress. Forced sex can increase the risk of psychological problems, leading to poor school performance and high-risk sexual behaviors, as well as physical health problems such complications from an unwanted pregnancy and STIs including HIV. ${ }^{49}$ To reduce psychological distress, a focus on prevention as well as treatment is needed. Women need social services and supports, and girls need a path toward a healthy and productive adulthood. Both may include a combination of educational, social, health, and economic services; in other words, a holistic or ecological approach. Some studies have focused on innovative interventions that have the potential to empower women and girls to be able to avoid forced sex and reduce concern about food insecurity. For instance, a study in South Africa found that a combined microfinance and health training intervention reduced women's experience of physical and/or sexual intimate partner violence in the past year compared to a control group. ${ }^{50} \mathrm{~A}$ novel and practical intervention study in Kenya found that self-defense training significantly reduced the incidence of sexual assault among girls. ${ }^{51}$ Another study by the Population Council used an asset building framework to create a program where girls could have their own savings account, which fostered self-esteem as well as offer a practical way to save for their future. ${ }^{52}$ Most important is keeping girls in a safe school setting through at least secondary school, which provides the framework for the breadth of holistic and ecological approaches to empower them as they become young women. Staying in school has been found to reduce the risk of HIV infection. ${ }^{53-55}$ Initiatives are underway to support these efforts. "Let Girls Learn" builds on the United States Agency for International Development campaign for girls' education, supports existing programs, and encourages other community-based nongovernmental organizations and governments to put more resources into girls' education. ${ }^{56}$ "Together for Girls" is a public-private partnership that stimulates policies and programs to prevent sexual violence and provides supportive care and services for victims of sexual violence. ${ }^{57}$ Given that $\sim 60 \%$ of Kenya's population is $\leq 24$ years of age,${ }^{58}$ initiatives like these have an enormous potential to improve the psychological health of girls and women and by extension, the physical and psychological health of their children and the society at large. Kenyan leadership and a strong national governance will be critical to the long-term success of public health initiatives. ${ }^{59}$

\section{Acknowledgments}

We extend our sincere appreciation to the study participants as well as the entire Kisumu community. In addition, we thank the members of the community engagement team for their tireless efforts in recruiting and following study participants, as well as keeping the community informed of the study's progress. This manuscript is published with the permission of the Director of KEMRI Center for Global Health Research.

\section{Disclosure}

The findings and conclusion in this report are those of the authors and do not necessarily represent the views of the Centers for Disease Control and Prevention. The authors report no conflicts of interest in this work.

\section{References}

1. Drapeau A, Marchand A, Beaulieu-Prevost D. Epidemiology of psychological distress, mental illnesses - understanding, prediction and control, Prof. Luciano LAbate (Ed.), InTech. Available from: http:// www.intechopen.com/books/mental-illnesses-understanding-prediction-and-control/epidemiology-of-psychological-distress. Accessed June 6, 2016.

2. Murray CJ, Vos T, Lozano R, et al. Disability-adjusted life years (DALYs) for 291 diseases and injuries in 21 regions, 1990-2010: a systematic analysis for the global burden of disease study 2010. Lancet. 2012; 380(9859):2197-2223.

3. Jacob KS, Sharan P, Mirza I, et al. Mental health systems in countries: where are we now? Lancet. 2007;370(9592):1061-1077.

4. Hamad R, Fernald LC, Karlan DS, Zinman J. Social and economic correlates of depressive symptoms and perceived stress in South African adults. J Epidemiol Community Health. 2008;62(6):538-544.

5. Kagotho N, Ssewamala FM. Correlates of depression among caregivers of children affected by HIV/AIDS in Uganda: findings from the SuubiMaka family study. AIDS Care. 2012;24(10):1226-1232.

6. Tafari S, Aboud FE, Larson CP. Determinants of mental illness in a rural Ethiopian adult population. Soc Sci Med. 1991;32(2):197-201.

7. Sipsma H, Ofori-Atta A, Canavan M, Osei-Akoto I, Udry C, Bradley EH. Poor mental health in Ghana: who is at risk? BMC Public Health. 2013;13:288.

8. Von Korff MS, Scott KM, Gureje O. Global Perspectives on MentalPhysical Co-Morbidity in the WHO World Mental Health Surveys. Cambridge, UK: Cambridge University Press; 2009.

9. UNAIDS. Fact Sheet Global Statistics; 2014. Available from: http:// www.unaids.org/sites/default/files/en/media/unaids/contentassets/ documents/factsheet/2014/20140716_FactSheet_en.pdf. Accessed February 3, 2016.

10. Ahaneku H, Ross MW, Nyoni JE, et al. Depression and HIV risk among men who have sex with men in Tanzania. AIDS Care. 2016;28(Suppl 1): 140-147.

11. Raiford J, Herbst JH, Carry M, Browne FA, Doherty I, Wechsberg WM. Low prospects and high risk: structural determinants of health associated with sexual risk among young African American women residing in resource-poor communities in the South. Am J Community Psychol. 2014; $54(3-4): 243-250$ 
12. Tadios Y, Davey G. Antiretroviral treatment adherence and its correlates in Addis Ababa, Ethiopia. Ethiop Med J. 2006;44(3):237-244.

13. Gardner LI, Marks G, Craw J, et al. Demographic, psychological, and behavioral modifiers of the antiretroviral treatment access study (ARTAS) intervention. AIDS Patient Care STDS. 2009;23(9):735-742.

14. National AIDS and STI Control Programme MoPhaS. Guidelines for HIV counselling and testing in Kenya; 2008. Available from: http:// www.who.int/hiv/topics/vct/policy/KenyaGuidelines_Final2009.pdf. Accessed February 18, 2016.

15. Kessler RC, Andrews G, Colpe LJ, et al. Short screening scales to monitor population prevalences and trends in non-specific psychological distress. Psychol Med. 2002;32(6):959-976.

16. Kessler RC, Green JG, Gruber MJ, et al. Screening for serious mental illness in the general population with the $\mathrm{K} 6$ screening scale: results from the WHO World Mental Health (WMH) survey initiative. Int $J$ Methods Psychiatr Res. 2010;19(Suppl 1):4-22.

17. Baggaley RF, Ganaba R, Filippi V, et al. Detecting depression after pregnancy: the validity of the K10 and K6 in Burkina Faso. Trop Med Int Health. 2007;12(10):1225-1229.

18. Tesfaye M, Hanlon C, Wondimagegn D, Alem A. Detecting postnatal common mental disorders in Addis Ababa, Ethiopia: validation of the Edinburgh Postnatal Depression Scale and Kessler Scales. $J$ Affect Disord. 2010;122(1-2):102-108.

19. Carta MG, Oumar FW, Moro MF, et al. Trauma- and stressor related disorders in the Tuareg refugees of a cAMP in burkina faso. Clin Pract Epidemiol Ment Health. 2013;9:189-195.

20. Prochaska JJ, Sung HY, Max W, Shi Y, Ong M. Validity study of the $\mathrm{K} 6$ scale as a measure of moderate mental distress based on mental health treatment need and utilization. Int $J$ Methods Psychiatr Res. 2012;21(2):88-97.

21. Kessler RC, Barker PR, Colpe LJ, et al. Screening for serious mental illness in the general population. Arch Gen Psychiatry. 2003;60(2): 184-189.

22. Agot K. HIV/AIDS interventions and the politics of the African woman's body. In: Nelson L, Seager J, editors. A Companion to Feminist Geography. Malden, MA: Blackwell Publishing; 2005.

23. Pratt LA, Dey AN, Cohen AJ. Characteristics of adults with serious psychological distress as measured by the K6 scale: United States, 2001-2004. Adv Data. 2007;(382):1-18.

24. Jenkins R, Njenga F, Okonji M, et al. Prevalence of common mental disorders in a rural district of Kenya, and socio-demographic risk factors. Int J Environ Res Public Health. 2012;9(5):1810-1819.

25. Ndetei DM, Muhangi J. The prevalence and clinical presentation of psychiatric illness in a rural setting in Kenya. Br J Psychiatry. 1979;135:269-272.

26. WHO. Preamble to the Constitution of the World Health Organization as adopted by the International Health Conference, New York, June 19-22, 1946; signed on July 22, 1946 by the representatives of 61 States (Official Records of the World Health Organization, no 2, p. 100) and entered into force on April 7, 1948.

27. WHO. Mental Health Action Plan 2013-2020; 2013. Available from: http://www.who.int/mental_health/action_plan_2013/en/. Accessed September 21, 2015.

28. Bingenheimer JB, Reed E. Risk for coerced sex among female youth in Ghana: roles of family context, school enrollment and relationship experience. Int Perspect Sex Reprod Health. 2014;40(4):184-195.

29. Tsai AC, Leiter K, Heisler M, et al. Prevalence and correlates of forced sex perpetration and victimization in Botswana and Swaziland. Am J Public Health. 2011;101(6):1068-1074.

30. Jewkes RK, Dunkle K, Nduna M, Shai N. Intimate partner violence, relationship power inequity, and incidence of HIV infection in young women in South Africa: a cohort study. Lancet. 2010;376(9734):41-48.

31. Moore AM, Awusabo-Asare K, Madise N, John-Langba J, KumiKyereme A. Coerced first sex among adolescent girls in sub-Saharan Africa: prevalence and context. Afr J Reprod Health. 2007;11(3): $62-82$.
32. Kalichman SC, Simbayi LC, Kaufman M, et al. Gender attitudes, sexual violence, and HIV/AIDS risks among men and women in Cape Town, South Africa. J Sex Res. 2005;42(4):299-305.

33. Obiero B. Sex, Consent and Power: A Case Study of Sex-Related Cultural Practices Among the Luo Community of Kenya [Dissertation]. Zimbabwe: University of Zimbabwe; 2010.

34. Oppong Asante K, Andoh-Arthur J. Prevalence and determinants of depressive symptoms among university students in Ghana. $J$ Affect Disord. 2015;171:161-166.

35. Maluccio JA, Palermo T, Kadiyala S, Rawat R. Improving healthrelated quality of life among people living with HIV: results from an impact evaluation of a food assistance program in Uganda. PloS One. 2015;10(8):e0135879.

36. McLaughlin KA, Green JG, Alegria M, et al. Food insecurity and mental disorders in a national sample of U.S. adolescents. $J$ Am Acad Child Adolesc Psychiatry. 2012;51(12):1293-1303.

37. Weaver LJ, Hadley C. Moving beyond hunger and nutrition: a systematic review of the evidence linking food insecurity and mental health in developing countries. Ecol Food Nutr. 2009;48(4):263-284.

38. Stewart R, Hirani V. Relationship between vitamin D levels and depressive symptoms in older residents from a national survey population. Psychosomatic Med. 2010;72(7):608-612.

39. Zhao G, Ford ES, Li C, Greenlund KJ, Croft JB, Balluz LS. Use of folic acid and vitamin supplementation among adults with depression and anxiety: a cross-sectional, population-based survey. Nutr J. 2011; 10:102.

40. Sanchez-Villegas A, Doreste J, Schlatter J, Pla J, Bes-Rastrollo M, Martinez-Gonzalez MA. Association between folate, vitamin B(6) and vitamin $\mathrm{B}(12)$ intake and depression in the SUN cohort study. J Hum Nutr Diet. 2009;22(2):122-133.

41. Jebena MG, Taha M, Nakajima M, et al. Household food insecurity and mental distress among pregnant women in Southwestern Ethiopia: a cross sectional study design. BMC Pregnancy Childbirth. 2015; $15: 250$.

42. Pitpitan EV, Kalichman SC, Eaton LA, et al. Co-occurring psychosocial problems and HIV risk among women attending drinking venues in a South African township: a syndemic approach. Ann Behav Med. 2013; 45(2):153-162.

43. Peltzer K, Naidoo P, Matseke G, Louw J, McHunu G, Tutshana B. Prevalence of post-traumatic stress symptoms and associated factors in tuberculosis (TB), TB retreatment and/or TB-HIV co-infected primary public health-care patients in three districts in South Africa. Psychol Health Med. 2013;18(4):387-397.

44. Melville J, Sniffen S, Crosby R, et al. Psychosocial impact of serological diagnosis of herpes simplex virus type 2: a qualitative assessment. Sex Transm Infect. 2003;79(4):280-285.

45. Stiffman AR, Dore P, Earls F, Cunningham R. The influence of mental health problems on AIDS-related risk behaviors in young adults. J Nerv Ment Dis. 1992;180(5):314-320.

46. Hoff RA, Beam-Goulet J, Rosenheck RA. Mental disorder as a risk factor for human immunodeficiency virus infection in a sample of veterans. J Nerv Ment Dis. 1997;185(9):556-560.

47. Brandt R. The mental health of people living with HIV/AIDS in Africa: a systematic review. Afr J AIDS Res. 2009;8(2):123-133.

48. Eaton NR, Krueger RF, Keyes KM, et al. Borderline personality disorder co-morbidity: relationship to the internalizing-externalizing structure of common mental disorders. Psychol Med. 2011;41(5):1041-1050.

49. Jejeebhoy SJ, Bott S. Non-Consensual Sexual Experiences of Young People: A Review of Evidence from Developing Countries. South \& East Asia Regional Working Paper, New Delhi, India: Population Council, No 16; 2003. Available from: http://citeseerx.ist.psu.edu/viewdoc/ download?doi=10.1.1.175.9529\&rep=rep1\&type=pdf. Accessed September 14, 2015.

50. Kim J, Ferrari G, Abramsky T, et al. Assessing the incremental effects of combining economic and health interventions: the IMAGE study in South Africa. Bull World Health Organ. 2009;87(11):824-832. 
51. Sinclair J, Sinclair L, Otieno E, Mulinge M, Kapphahn C, Golden NH. A self-defense program reduces the incidence of sexual assault in Kenyan adolescent girls. J Adolesc Health. 2013;53(3):374-380.

52. Austrian KM, Wambugu A, Ghati D, Kariuki E. Safe and Smart Savings for Vulnerable Girls in Kenya and Uganda. Population Council; 2012. Available from: http://www.popcouncil.org/uploads/pdfs/2012PGY_ SmartSavingsProgramBrief.pdf. Accessed September 30, 2015.

53. Pettifor AE, Levandowski BA, MacPhail C, Padian NS, Cohen MS, Rees HV. Keep them in school: the importance of education as a protective factor against HIV infection among young South African women. Int J Epidemiol. 2008;37(6):1266-1273.

54. Pettifor A, MacPhail C, Hughes JP, et al. The effect of a conditional cash transfer on HIV incidence in young women in rural South Africa (HPTN 068): a phase 3, randomised controlled trial. Lancet Glob Health. 2016;4(12):e978-e988.

55. Baird SJ, Garfein RS, McIntosh CT, Ozler B. Effect of a cash transfer programme for schooling on prevalence of HIV and herpes simplex type 2 in Malawi: a cluster randomised trial. Lancet. 2012;379(9823): $1320-1329$.
56. White House Fact Sheet: Let Girls Learn; 2015. Available from: https:// www.whitehouse.gov/sites/default/files/image/files/let_girls_learn_ fact_sheet_03032015.pdf. Accessed September 29, 2015.

57. CDC. Together for Girls: We Can End Sexual Violence. Available from: http://www.cdc.gov/violenceprevention/pdf/TogetherforGirlsBklt-a. pdf. Accessed December 4, 2015.

58. Central Intelligence Agency. The world factbook; 2016. Available from: https://www.cia.gov/library/publications/the-world-factbook/ geos/ke.html. Accessed February 3, 2016.

59. Cooke J. Public Health in Africa: A Report of the CSIS Global Health Policy Center; 2009. Available from: http://csis.org/files/media/csis/ pubs/090420_cooke_pubhealthafrica_web.pdf. Accessed February 8, 2016.

\section{Publish your work in this journal}

The International Journal of Women's Health is an international, peerreviewed open-access journal publishing original research, reports, editorials, reviews and commentaries on all aspects of women's healthcare including gynecology, obstetrics, and breast cancer. The manuscript management system is completely online and includes

\section{Dovepress}

a very quick and fair peer-review system, which is all easy to use. Visit http://www.dovepress.com/testimonials.php to read real quotes from published authors. 